Ambiente \& Água - An Interdisciplinary Journal of Applied Science
ISSN 1980-993X - doi:10.4136/1980-993X
www.ambi-agua.net
E-mail: ambi.agua@gmail.com

\title{
Avaliação bacteriológica e físico-química de águas de irrigação, solo e alface (Lactuca sativa $\mathrm{L}$.)
}

\author{
doi:10.4136/ambi-agua.1829
}

Received: 21 Dec. 2015; Accepted: 20 Apr. 2016

\section{Karine Scherer ${ }^{1}$; Camille Eichelberger Granada ${ }^{1}$; Simone Stülp ${ }^{2}$; Raul Antonio Sperotto ${ }^{*}$}

\author{
Centro Universitário UNIVATES, Lajeado, RS, Brasil \\ ${ }^{1}$ Programa de Pós-Graduação em Biotecnologia (PPGBiotec) \\ ${ }^{2}$ Programa de Pós-Graduação em Ambiente e Desenvolvimento (PPGAD) \\ *Autor correspondente: e-mail: rasperotto@univates.br, \\ kascherer@universo.univates.br, cegranada@univates.br, \\ stulp@univates.br
}

\section{RESUMO}

A contaminação de hortaliças por micro-organismos patogênicos está diretamente relacionada com a qualidade das águas de irrigação utilizadas na agricultura e com o solo onde se encontram. Com o objetivo de se verificar as condições empregadas na produção de alface (Lactuca sativa L.) em três pequenas propriedades do interior do Rio Grande do Sul (Brasil), foram avaliadas a condição físico-química das águas de irrigação, e a condição microbiológica das águas, solo e folhas de alface. As análises bacteriológicas das águas de irrigação, hortaliças e do solo foram realizadas usando a técnica dos tubos múltiplos ou por contagem em placa, e levou em conta os coliformes totais, coliformes termotolerantes, e presença ou ausência de Escherichia coli, Salmonella sp. e Listeria sp.. As análises físico-químicas realizadas nas águas de irrigação foram $\mathrm{pH}$, turbidez, oxigênio dissolvido, demanda bioquímica de oxigênio, carbono orgânico total e nitrogênio total. As análises bacteriológicas nas águas de irrigação indicaram a ausência de Salmonella sp. e Listeria sp.. Entretanto, foi detectada a presença de E. coli e valores acima do permitido pela legislação para coliformes termotolerantes. Desta forma, estas águas se encontram fora dos padrões estabelecidos pela Resolução CONAMA $n^{\circ} 357$. A pesquisa também mostrou a presença de E. coli, Salmonella sp. e Listeria sp. nas hortaliças irrigadas, sugerindo que a fonte de contaminação por Salmonella sp. e Listeria sp. deve ser a partir do solo, e não a partir da água de irrigação. Os dados físico-químicos mostraram que apenas uma das propriedades analisadas apresentou todos os parâmetros adequados, segundo a legislação vigente para águas doces de classe 1. Portanto, apenas uma das propriedades apresentou condições físico-químicas para ser utilizada na irrigação de alface, embora nenhuma tenha apresentado condições higiênico-sanitárias para tal uso.

Palavras-chave: hortaliças, micro-organismos, parâmetros físico-químicos. 


\title{
Bacteriological and physico-chemical analysis of irrigation water, soil and lettuce (Lactuca sativa L.)
}

\begin{abstract}
The contamination of greenery by pathogenic microorganisms is directly related to the quality of irrigation water used in agriculture and to the soil where the greenery is located. In order to verify the conditions surrounding lettuce (Lactuca sativa L.) production at three small properties of Rio Grande do Sul State, Brazil, we evaluated the physico-chemical conditions of irrigation water as well as the microbiological condition of water, soil and lettuce leaves. Bacteriological analyses of the irrigation water, greenery and soil were performed using the multiple tubes or plate-counting techniques, and the total coliforms, thermo-tolerant coliforms, and presence or absence of Escherichia coli, Salmonella sp. and Listeria sp. was evaluated. The irrigation water was analyzed to determine $\mathrm{pH}$, turbidity, dissolved oxygen, biochemical oxygen demand, total organic carbon and total nitrogen. Bacteriological analysis on the irrigation water indicated the absence of Salmonella sp. and Listeria sp.. However, we detected the presence of $E$. coli and higher thermo-tolerant coliform levels than that established by current legislation. Thus, these water samples do not conform to the standards established by the CONAMA $n^{\circ} 357$ Resolution. Our analyses also showed the presence of E. coli, Salmonella sp. e Listeria sp. on the irrigated greenery, suggesting that the source of the Salmonella sp. and Listeria sp. contamination must be the soil, rather than the irrigation water. Physico-chemical analyses showed that only one of the analyzed properties conforms to the standards established by current legislation for Class 1 fresh water. Therefore, only one of the properties presented the physico-chemical conditions appropriate for lettuce irrigation, although no property presented hygienic sanitary conditions for such use.
\end{abstract}

Keywords: greenery, microorganisms, physico-chemical parameters.

\section{INTRODUÇÃO}

Anualmente a agricultura é responsável por $87 \%$ do consumo total de água no mundo. Em termos globais, a indústria usa $24 \%$ e consome $4 \%$ da água hoje aproveitada, e seu uso excessivo pode acarretar a diminuição do volume ou o esgotamento dos aquíferos subterrâneos. Em áreas sem rede de esgotos, a contaminação das águas pode ocorrer por efluentes domésticos, nos quais existem elevadas concentrações de produtos químicos e variadas concentrações de organismos patogênicos, podendo causar impactos significativos sobre a saúde humana (Schmidt, 2006).

O desenvolvimento da agricultura e o uso de novas tecnologias para o aumento da produtividade são extremamente dependentes da disponibilidade dos recursos hídricos (Meng et al., 2016). A maioria dos produtores rurais não possui orientação sobre a importância das características físico-químicas e microbiológicas da água de irrigação para o desenvolvimento da planta e para produtividade da lavoura, principalmente para o cultivo de hortaliças. Estas características podem ser um indicativo das condições sanitárias da produção, pois ao carregar bactérias patogênicas, a água pode atuar como veículo de disseminação de doenças, contaminando o solo e toda produção agrícola (Jobbins e Alexander, 2015). Assim, o conhecimento da qualidade da água é de fundamental importância para a produtividade e para o controle da disseminação de doenças microbianas em áreas de produção (van Dyk et al., 2016).

O principal teste realizado para a avaliação das condições microbiológicas da água é a detecção de bactérias do grupo coliformes, que são os principais indicadores de poluição fecal, pois habitam o trato intestinal e são eliminados em grande número com as fezes. Os 
principais parâmetros físico-químicos utilizados na avaliação da qualidade da água utilizada para irrigação são: $\mathrm{pH}$, turbidez, demanda bioquímica de oxigênio (DBO), $\mathrm{C}$ orgânico total e $\mathrm{N}$ total (Lee et al., 2013).

A alface (Lactuca sativa L.) é uma hortaliça que pode ser cultivada durante todo o ano, sendo que, em canteiros de terra, estas plantas ficam em contato direto com o solo durante todo o seu período de desenvolvimento. Do ponto de vista nutricional, possui elevado teor de vitamina $\mathrm{A}$ em suas folhas, sendo rica em sais de $\mathrm{Ca}$ e Fe, apresentando baixo valor calórico e baixo custo de produção. Tudo isso faz da alface uma das hortaliças mais comercializadas e consumidas no país. Por ser consumida crua, pode ser responsável pela transmissão de diversas doenças. Estudos indicam que a própria estrutura das plantas de alface influencia na sobrevivência de micro-organismos, sendo estes, os principais transmissores de doenças associadas à contaminação alimentar (Holvoet et al., 2014).

A necessidade de prevenir e reduzir os riscos de contaminações por substâncias químicas e micro-organismos nocivos à saúde se torna cada vez maior, tendo em vista que muitas hortas brasileiras podem estar sendo irrigadas com água contaminada por pesticidas e material fecal. Assim, o objetivo deste trabalho foi avaliar parâmetros físico-químicos e microbiológicos das águas de irrigação de alface de três propriedades rurais, bem como a qualidade do solo e das plantas.

\section{MATERIAL E MÉTODOS}

\subsection{Pontos amostrados e coleta do material}

Foram efetuadas avaliações em triplicatas nas águas de irrigação (açudes), no solo e em plantas de alface de três importantes propriedades rurais do Vale do Taquari/RS (indicadas pela Emater/RS - Regional Lajeado), nos meses de maio, junho e julho de 2013, totalizando nove amostras em cada ponto. As coletas das amostras de água foram realizadas nos açudes, numa profundidade de aproximadamente $30 \mathrm{~cm}$ da superfície, em local próximo à bomba de sucção (aproximadamente $1 \mathrm{~m}$ ), conforme Parron et al. (2011). Em recipientes estéreis, mensalmente foram coletadas amostras de 1,0 L de água utilizada na irrigação (para as análises bacteriológicas e físico-químicas), $100 \mathrm{~g}$ de solo e $100 \mathrm{~g}$ de folhas de alface cultivadas diretamente no solo irrigado, em cada uma das propriedades visitadas, conforme Borges Filho e Machado (2013). As coletas de solo foram realizadas com espátulas e sacos Stomacher estéreis, num raio de aproximadamente $15 \mathrm{~cm}$ ao redor das plantas de alface, e com profundidade de aproximadamente $15 \mathrm{~cm}$. As coletas de alface individualizadas foram realizadas com luvas e faca estéril, separando a parte aérea das raízes para evitar contaminação. As amostras foram processadas conforme Borges Filho e Machado (2013). As coordenadas geográficas dos pontos de coleta foram: $29^{\circ} 27^{\prime} 31^{\prime \prime} \mathrm{S}$ e $52^{\circ} 01^{\prime} 01^{\prime \prime} \mathrm{W}$ para a propriedade $1 ; 29^{\circ} 25^{\prime} 06^{\prime \prime} \mathrm{S}$ e $52^{\circ} 02^{\prime} 10^{\prime \prime} \mathrm{W}$ para a propriedade 2 ; e $29^{\circ} 25^{\prime} 32^{\prime \prime} \mathrm{S}$ e $51^{\circ} 59^{\prime} 23^{\prime \prime} \mathrm{W}$ para a propriedade 3 .

\subsection{Análises bacteriológicas}

As análises bacteriológicas foram realizadas no Laboratório de Microbiologia do Centro Universitário UNIVATES. As análises das águas de irrigação foram realizadas por meio da Técnica dos Tubos Múltiplos (utilizando a Tabela de Hoskins para séries de três tubos), e as análises de solo e folhas de alface foram realizadas por Contagem Padrão em Placas. Foram analisados os coliformes totais, coliformes termotolerantes, presença ou ausência de Escherichia coli, Salmonella sp. e Listeria sp., de acordo com a metodologia descrita na Instrução Normativa 62/2003, do Ministério da Agricultura, Pecuária e Abastecimento (MAPA). No caso da detecção de Salmonella sp. e Listeria sp., por não existir uma legislação vigente para águas, para essas análises seguimos a Instrução Normativa 62, utilizando 
$25 \mathrm{~mL}$ de água.

\subsection{Análises físico-químicas e análise estatística}

As análises físico-químicas de $\mathrm{pH}$, Turbidez, Oxigênio dissolvido (OD), Demanda Bioquímica de Oxigênio (DBO), Carbono Orgânico Total (COT) e Nitrogênio Total (NT) foram realizadas no Laboratório de Química Geral do Centro Universitário UNIVATES, utilizando-se, respectivamente, protocolos padrões (Parron et al., 2011) e os seguintes equipamentos: medidor de pH Digimed DM-20, Turbidímetro Digimed DM TU, medidor de $\mathrm{O}_{2}$ da marca Digimed DM 4P, medidor Oxitop WTW e medidor de nitrogênio TNM1 Shimadzu. Os resultados obtidos foram submetidos à análise de variância (One-Way ANOVA), seguido pelo teste de Tukey $(\mathrm{p} \leq 0,05)$, utilizando o software SPSS 21.0.

\section{RESULTADOS E DISCUSSÃO}

A Tabela 1 mostra as contagens de coliformes totais, termotolerantes e Escherichia coli, Salmonella sp. e Listeria sp. nas águas de irrigação.

Tabela 1. Coliformes totais e termotolerantes em amostras de águas de irrigação (NMP $\left.100 \mathrm{~mL}^{-1}\right)$ e presença ou ausência de E. coli, Salmonella sp. e Listeria sp..

\begin{tabular}{ccccccc}
\hline Propriedade & Amostras & $\begin{array}{c}\text { Coliformes } \\
\text { Totais } \\
\left(\text { NMP } 100 \mathrm{~mL}^{-1}\right)\end{array}$ & $\begin{array}{c}\text { Coliformes } \\
\text { Termotolerantes } \\
\left(\text { NMP } 100 \mathrm{~mL}^{-1}\right)\end{array}$ & E. coli & Salmonella sp. & Listeria sp. \\
\hline 1 & 1 & $1,1 \times 10^{3}$ & $1,1 \times 10^{3}$ & Presente & Ausente & Ausente \\
& 2 & $1,1 \times 10^{3}$ & $4,6 \times 10^{2}$ & Presente & Ausente & Ausente \\
& 3 & $1,1 \times 10^{3}$ & $4,6 \times 10^{2}$ & Presente & Ausente & Ausente \\
2 & 1 & $>1,1 \times 10^{3}$ & $>1,1 \times 10^{3}$ & Presente & Ausente & Ausente \\
& 2 & $1,1 \times 10^{3}$ & $4,6 \times 10^{2}$ & Presente & Ausente & Ausente \\
& 3 & $>1,1 \times 10^{3}$ & $>1,1 \times 10^{3}$ & Presente & Ausente & Ausente \\
& 1 & $>1,1 \times 10^{3}$ & $>1,1 \times 10^{3}$ & Presente & Ausente & Ausente \\
& 2 & $1,1 \times 10^{3}$ & $1,1 \times 10^{3}$ & Presente & Ausente & Ausente \\
& 3 & $1,1 \times 10^{3}$ & $1,1 \times 10^{3}$ & Presente & Ausente & Ausente \\
\hline
\end{tabular}

Os valores de coliformes termotolerantes (Tabela 1) encontram-se acima do limite de 200 NMP $100 \mathrm{~mL}^{-1}$, estabelecido na Resolução CONAMA n ${ }^{\circ} 357 / 2005$. Entretanto, uma conclusão final só poderia ser obtida se essas coletas fossem realizadas periodicamente em cada uma das propriedades (seis amostras no período de um ano). Assim, no momento da coleta, a água dos açudes das três propriedades visitadas foi considerada inapropriada para uso no cultivo de hortaliças consumidas cruas. A presença de bactérias do grupo coliformes em águas pode ser um indicativo que esta recebeu material fecal ou esgotos. Jensen et al. (2015) relatou que a utilização de águas contaminadas associada a falta de padrão sanitário em decorrência do manuseio, transporte e pós-colheita das hortaliças, tem sido porta de entrada de $E$. coli na cadeia alimentar através do consumo das hortaliças cruas, como por exemplo a alface. Cabe ressaltar que a presença de E. coli per se não representa, obrigatoriamente, um agente patogênico. Assim como verificado neste trabalho, Gonçalves et al. (2000) mostraram que amostras de água de fontes de propriedades rurais do município de Agudo (RS) apresentavam valores elevados de coliformes termotolerantes, atuando como uma potencial fonte de infecção.

As análises bacteriológicas também indicaram a ausência de Salmonella sp. e Listeria sp. 
nas águas de irrigação amostradas. Estes micro-organismos fazem parte de uma importante classe de patógenos humanos, e, apesar de não existir uma legislação brasileira para estes micro-organismos, a legislação europeia vigente estipula que estes devem estar ausentes em $25 \mathrm{~mL}$ de água. Entretanto, é importante destacar que esses resultados deveriam ser confirmados por outra metodologia mais sensível, devido à alta probabilidade de resultados falso-negativos na detecção de patógenos em água (Marquezi et al., 2010).

A Tabela 2 apresenta os resultados das análises bacteriológicas em amostras de solo utilizadas no cultivo de alface.

Tabela 2. Coliformes totais e termotolerantes em amostras de solo (UFC $\mathrm{g}^{-1}$ ) e presença ou ausência de E. coli, Salmonella sp. e Listeria sp..

\begin{tabular}{|c|c|c|c|c|c|c|}
\hline Propriedade & Amostras & $\begin{array}{l}\text { Coliformes } \\
\text { Totais } \\
\left(\mathrm{UFC}^{-1}\right)\end{array}$ & $\begin{array}{c}\text { Coliformes } \\
\text { Termotolerantes } \\
\left(\mathrm{UFC}^{-1}\right)\end{array}$ & E. coli & Salmonella sp. & Listeria sp. \\
\hline \multirow{3}{*}{1} & 1 & $1,5 \times 10^{6}$ & $<1,0 \times 10^{4}$ & Presente & Ausente & Presente \\
\hline & 2 & $<1,0 \times 10^{4}$ & $<1,0 \times 10^{4}$ & Ausente & Presente & Presente \\
\hline & 3 & $3,4 \times 10^{5}$ & $<1,0 \times 10^{4}$ & Presente & Presente & Presente \\
\hline \multirow{3}{*}{2} & 1 & $<1,0 \times 10^{4}$ & $<1,0 \times 10^{4}$ & Ausente & Presente & Presente \\
\hline & 2 & $<1,0 \times 10^{4}$ & $<1,0 \times 10^{4}$ & Ausente & Presente & Presente \\
\hline & 3 & $<1,0 \times 10^{4}$ & $<1,0 \times 10^{4}$ & Ausente & Presente & Ausente \\
\hline \multirow{3}{*}{3} & 1 & $<1,0 \times 10^{4}$ & $<1,0 \times 10^{4}$ & Ausente & Ausente & Ausente \\
\hline & 2 & $<1,0 \times 10^{4}$ & $<1,0 \times 10^{4}$ & Ausente & Presente & Presente \\
\hline & 3 & $<1,0 \times 10^{4}$ & $<1,0 \times 10^{4}$ & Ausente & Presente & Ausente \\
\hline
\end{tabular}

As amostras de solos analisadas apresentaram altos valores de coliformes totais e termotolerantes entre $<1,0 \times 10^{4} \mathrm{UFC} \mathrm{g}^{-1}$ e $1,5 \times 10^{6} \mathrm{UFC} \mathrm{g}^{-1}$ (Tabela 2). O solo é o habitat natural de muitos micro-organismos, inclusive os pertencentes ao grupo dos coliformes. A irrigação de hortaliças com águas que apresentam altos níveis de coliformes (como as encontradas no presente trabalho) podem estar contribuindo para o aumento ou manutenção da população deste grupo de micro-organismos. Portanto, parte destes coliformes pode ser oriunda da água utilizada na irrigação destas plantas. Também foi detectada a presença dos gêneros bacterianos Salmonella sp. e Listeria sp. (Tabela 2). Segundo Strawn et al. (2013), Salmonella sp. e Listeria sp. são micro-organismos muito resistentes às condições adversas do meio ambiente, e como não foram encontradas nas águas de irrigação, muito provavelmente são provenientes do próprio solo da região.

A Tabela 3 apresenta os resultados das análises bacteriológicas em amostras de folhas de alface.

A Resolução RDC n 12/2001 da Agência Nacional de Vigilância Sanitária (ANVISA) estabelece que o número máximo de coliformes termotolerantes aceitável em hortaliças consumidas cruas é de $100 \mathrm{UFC} \mathrm{g}^{-1}$ de hortaliça. Assim, as amostras de alface coletadas encontraram-se dentro dos limites permitidos nesta resolução (Tabela 3). Também foi observada a presença de E. coli em pelo menos duas amostras coletadas em cada propriedade. Segundo Guimarães et al. (2003), vários estudos realizados no Brasil mostraram alto grau de contaminação por coliformes termotolerantes em hortaliças e relataram ainda que esta contaminação pode ter sido transmitida pela água usada na irrigação, pois ela também apresentou E. coli. De acordo com Takayanagui et al. (2000), das 129 hortas no interior do 
Estado de São Paulo que cultivavam hortaliças como alface, almeirão e agrião, foi constatado que $17 \%$ dessas apresentaram contaminação por coliformes termotolerantes provenientes das águas de irrigação. Em um estudo mais recente, Frittoli e Rodrigues (2014) verificaram que $35 \%$ das amostras de hortaliças minimamente processadas apresentaram contagem de coliformes termotolerantes acima do estabelecido pela legislação. Contagens elevadas de coliformes totais também foram encontradas nos produtos $(65 \%)$, indicando condições inadequadas de higiene durante o processamento, comprometendo, assim, sua qualidade microbiológica.

Tabela 3. Coliformes totais e termotolerantes em amostras de alface (UFC $\mathrm{g}^{-1}$ ) e presença ou ausência de E. coli, Salmonella sp. e Listeria sp..

\begin{tabular}{|c|c|c|c|c|c|c|}
\hline Propriedade & Amostras & $\begin{array}{l}\text { Coliformes } \\
\text { Totais } \\
\left(\mathrm{UFC} \mathrm{g}^{-1}\right)\end{array}$ & $\begin{array}{c}\text { Coliformes } \\
\text { Termotolerantes } \\
\left(\mathrm{UFC} \mathrm{g}^{-1}\right)\end{array}$ & E. coli & Salmonella sp. & Listeria $s p$. \\
\hline \multirow{3}{*}{1} & 1 & Incontável* & $<100$ & Presente & Ausente & Presente \\
\hline & 2 & Incontável* & $<100$ & Presente & Ausente & Ausente \\
\hline & 3 & $<100$ & $<100$ & Ausente & Presente & Ausente \\
\hline \multirow{3}{*}{2} & 1 & Incontável* & $<100$ & Ausente & Ausente & Ausente \\
\hline & 2 & Incontável* & $<100$ & Presente & Presente & Ausente \\
\hline & 3 & Incontável* & $<100$ & Presente & Presente & Presente \\
\hline \multirow{3}{*}{3} & 1 & $<100$ & $<100$ & Ausente & Presente & Ausente \\
\hline & 2 & $<100$ & $<100$ & Presente & Ausente & Ausente \\
\hline & 3 & $1,1 \times 10^{4}$ & $<100$ & Presente & Presente & Presente \\
\hline
\end{tabular}

"Concentração muito alta de micro-organismos na diluição $10^{-3}$.

Também foi observada a presença de Salmonella $s p$. em pelo menos uma amostra coletada em cada propriedade. Com relação à presença de Salmonella sp., a Resolução RDC $n^{\circ}$ 12/2001 da ANVISA determina que, em hortaliças frescas, refrigeradas ou congeladas, consumidas cruas, este micro-organismo deve estar ausente em $25 \mathrm{~g}$ de produto. Os alimentos de origem animal são os principais transmissores de Salmonella sp., mas vários estudos já detectaram a presença deste micro-organismo em produtos de origem vegetal. Takayanagui et al. (2000), encontraram Salmonella sp. em 3,1\% das hortaliças de 129 hortas pesquisadas. Palú et al. (2002) encontraram Salmonella sp. em 16,6\% das amostras de vegetais crus comercializados em restaurantes da cidade do Rio de Janeiro. Conforme estudos sobre a transmissão de doenças por meio de alimentos, tem surgido, nos últimos anos, um novo cenário epidemiológico, caracterizado pela rapidez de propagação, alta patogenicidade e caráter cosmopolita dos micro-organismos, em especial, Listeria sp. e Salmonella sp. (Allende e Monaghan, 2015). Outro estudo, realizado por Oliveira e Junqueira (2005), mostrou que em locais onde as práticas higiênico-sanitárias não são corretas, a utilização de água contaminada para irrigar hortaliças ou até mesmo a utilização de esterco bovino como adubo pode aumentar o risco de contaminação por Salmonella sp. e outros patógenos.

Neste trabalho, verificou-se a ocorrência de Listeria sp. em 33,3\% das amostras de alface de cada propriedade. Vongkamjan et al. (2016) mostraram que foi detectada a presença de Listeria sp. em apenas 7,5\% das amostras analisadas para consumo direto. Em estudo realizado por Brandão et al. (2013), no Brasil, apenas 7,2\% das amostras de hortaliças in natura e em forma de salada, mostraram a presença de Listeria monocytogenes.

Conforme Allende e Monaghan (2015), a contaminação de hortaliças por micro-organismos durante o seu cultivo ocorre principalmente pela irrigação com água 
contaminada ou pela utilização de adubo com dejetos animais. Além disso, existem outros fatores que contribuem para contaminar esta água com micro-organismos: a proximidade com áreas domésticas ou lixões, currais, canais, esgotos, fossas, presença de adubo orgânico próximo das fontes, declividade do solo, presença de animais, poços artesianos com más instalações e utilização de água de rios ou riachos contaminados (Oliveira et al., 2001).

Para estarem adequadas ao consumo humano, as características físicas esperadas para que a água seja de qualidade são que esta seja transparente, incolor, inodora e insípida. Os parâmetros químicos são extremamente importantes para se caracterizar a qualidade da água, pois permitem classificá-la por seu conteúdo mineral, determinar o grau de contaminação, caracterizar picos de concentração de poluentes tóxicos e as possíveis fontes, além de avaliar o equilíbrio bioquímico que é necessário para a manutenção da vida aquática (Singh et al., 2005).

A Figura 1 apresenta os parâmetros físico-químicos das águas de irrigação estudadas neste trabalho.
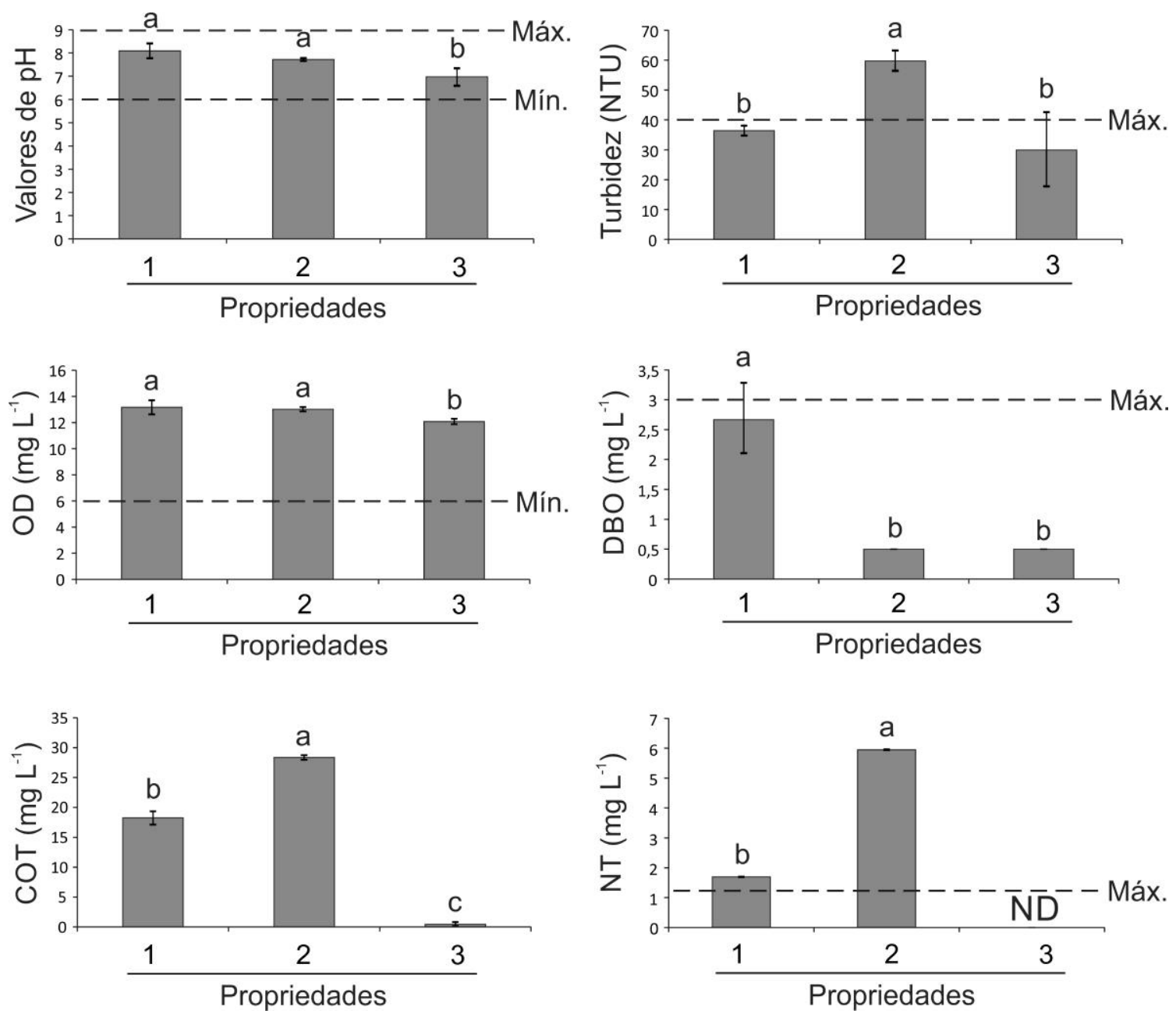

Figura 1. Análises de pH, Turbidez, Oxigênio Dissolvido (OD), Demanda Bioquímica de Oxigênio (DBO), Carbono Orgânico Total (COT) e Nitrogênio Total (NT) em águas de irrigação. Os valores apresentados são a média de nove amostras \pm desvio padrão. Médias com letras diferentes indicam diferença estatisticamente significante $(p \leq 0,05)$. As linhas tracejadas indicam o(s) valor(es) limite(s), segundo a Resolução CONAMA nº 357/2005 para águas doces de classe 1. Alguns valores de desvio-padrão são muito pequenos para serem visíveis nos gráficos.

Nota: Mín. = Valor mínimo permitido pela legislação vigente; Máx. = Valor máximo permitido pela legislação vigente; NTU = Nephelometric Turbidity Unit; ND = não detectado. 
As análises físico-químicas das águas de irrigação analisadas mostraram valores de $\mathrm{pH}$ entre 6,82 e 8,34 (Figura 1). Os valores encontrados nas três propriedades ficaram dentro dos limites estabelecidos pela legislação vigente, que recomenda a faixa entre 6,0 e 9,0 como padrão para consumo humano. Nas propriedades 1 e 2 , os valores de $\mathrm{pH}$ foram considerados estatisticamente iguais, variando apenas na propriedade 3 , que apresentou menor valor. Conforme Barros et al. (1999), quando os valores de $\mathrm{pH}$ encontram-se entre 6,9 e 7,4, pode ocorrer a formação de bicarbonatos, o que torna as águas de irrigação alcalinas. Este fato também pode causar problemas nos equipamentos utilizados para a irrigação, como corrosão ou precipitação da matéria orgânica na tubulação, além de adsorção de nitratos. Outro estudo mostra que pode ocorrer baixa disponibilidade de nutrientes a serem absorvidos pelas plantas, caso o $\mathrm{pH}$ esteja muito elevado, interferindo principalmente no crescimento de hortaliças (Forsythe, 2002). Conforme Casali (2008), a amplitude nos valores de pH justifica-se pela composição química das águas, que pode ser influenciada pela formação geológica que armazena a água, pelo seu nível de contaminação e pelo sistema de captação utilizado.

A turbidez indica a presença de sólidos suspensos na água, diminuindo sua transparência. No caso das águas de irrigação analisadas, a turbidez variou de 19,9 NTU a 63,0 NTU (Figura 1). Para águas utilizadas para irrigação de hortaliças cruas, a legislação exige valores de turbidez inferiores a 40 NTU (Resolução CONAMA n 357/2005). No caso das águas da propriedade 2, os níveis de turbidez mostraram-se elevados (63 NTU), sendo indicativo da presença de partículas presentes na água, que podem ser constituídas por plâncton, bactérias, argilas ou fontes de poluição.

Os valores de OD encontrados estiveram na faixa entre 11,8 e 13,6 $\mathrm{mg} \mathrm{L}^{-1}$ (Figura 1). Estes elevados valores estão em conformidade com a Resolução CONAMA n ${ }^{\circ} 357 / 2005$, que estabelece que os valores de OD não devem ser inferiores a $6,0 \mathrm{mg} \mathrm{L}^{-1}$, e podem ser devidos ao bombeamento da água nos açudes. A propriedade 3 apresentou a menor média de concentração de OD $\left(12,1 \mathrm{mg} \mathrm{L}^{-1}\right)$. As águas que apresentam altas concentrações de OD são consideradas não poluídas, pois indicam baixos níveis de decomposição (Kong e Hong, 2014). Na prática, embora este não seja um parâmetro de qualidade da água para irrigação, ele funciona como indicativo de poluição orgânica.

Os valores de DBO determinados estiveram no intervalo entre 0,5 e $3,0 \mathrm{mg} \mathrm{L}^{-1}$ (Figura 1), em conformidade com a Resolução CONAMA ${ }^{\circ} 357 / 2005$, que estabelece que a DBO deve ser inferior a $3,0 \mathrm{mg} \mathrm{L}^{-1}$. Os valores obtidos sugerem que há uma pequena quantidade de substâncias biodegradáveis presentes, sem grandes descargas de matéria orgânica ou crescimento exagerado do plâncton, sendo que a propriedade 1 apresentou valor de DBO maior que as demais.

As taxas de COT também apresentaram resultados diferentes nas três propriedades pesquisadas (Figura 1). A propriedade 3 apresentou valor de COT menor que as propriedades 1 e 2. Devido ao fato da legislação brasileira não possuir valores de referência de COT para águas doces de classe 1 (apenas para água salina ou salobra), não é possível afirmar a partir deste parâmetro que as águas dessas propriedades apresentam valores adequados para irrigação de hortaliças. Entretanto, a concentração de COT normalmente está relacionada com a concentração de matéria orgânica.

De acordo com a Resolução CONAMA n ${ }^{\circ} 357 / 2005$, os valores limites de NT são de até $1,3 \mathrm{mg} \mathrm{L}^{-1}$ para ambientes lênticos. No caso das águas de irrigação analisadas, somente a propriedade 3 apresenta valores de NT inferiores ao limite máximo estabelecido (Figura 1). Considerando que essas análises foram realizadas em pequenas propriedades rurais, o NT pode ser proveniente de despejos domésticos, excrementos animais e fertilizantes químicos, podendo indicar contaminação ambiental.

Somente a água de irrigação da propriedade 3 apresentou todas as características 
físico-químicas em consonância com os padrões estabelecidos pela legislação vigente. As propriedades 1 e 2 apresentaram valores de NT fora dos padrões aceitáveis para uso na irrigação de hortaliças, e somente a propriedade 2 apresentou valores de turbidez inadequados. Apesar do reduzido número de amostras analisadas (triplicatas biológicas e triplicata experimental), os valores das nove replicatas mostraram-se pouco variáveis, o que possibilita uma inferência estatística confiável mesmo com um número amostral pequeno.

\section{CONCLUSÃO}

A qualidade da água não foi satisfatória para o uso na irrigação, sendo que todas as amostras de água de irrigação apresentaram coliformes termotolerantes e E. coli. Segundo as condições de realização do nosso estudo, as análises físico-químicas mostraram que somente a propriedade 3 apresenta todos os parâmetros em consonância com os limites estabelecidos pela legislação vigente. A implantação de boas práticas agrícolas seria uma forma de minimizar os riscos potenciais à saúde do consumidor, contribuindo para a produção de hortaliças de boa qualidade higiênico-sanitária.

\section{REFERÊNCIAS}

ALLENDE, A.; MONAGHAN, J. Irrigation water quality for leafy crops: a perspective of risks and potential solutions. International Journal of Environmental Research in Public Health, v. 12, p. 7457-7477, 2015. http://dx.doi.org/10.3390/ijerph120707457

BARROS, A. J; CEBALlOS, B. S. O.; KÖNIG, A.; GHEYI, H. R. Avaliação sanitária e físico-química das águas para irrigação de hortaliças no agreste e brejo paraibano. Revista Brasileira de Engenharia Agrícola e Ambiental, v. 3, n. 3, p. 355-360, 1999.

BORGES FILHO, E. L.; MACHADO, E. C. Evaluation of microbial soil and vegetables after the addition of organic fertilizers: a case study of the vegetable-garden. eScientia, v. 6, n. 1, p. 8-15, 2013.

BRANDÃO, M. L. L.; BISPO, F. C. P.; ALMEIDA, D. O.; ROSAS, C. O.; BRICIO, S. M. L.; MARIN, V. A. Listeria monocytogenes in green vegetables: isolation and serotyping. Revista do Instituto Adolfo Lutz, v. 72, n. 1, p. 116-121, 2013.

CASALI, C. A. Qualidade da água para consumo humano ofertada em escolas e comunidades rurais da região central do Rio Grande do Sul. 2008. Dissertação (Mestrado em Ciência do Solo) - Universidade Federal de Santa Maria, Santa Maria, 2008 .

FORSYTHE, S. J. Microbiologia da segurança alimentar. Porto Alegre: Artmed, 2002. $424 \mathrm{p}$.

FRITTOLI, R. B.; RODRIGUES, L. H. Analysis of fecal coliform and Salmonella sp. in samples of minimally processed vegetables. Revista Científica da FHOUNIARARAS, v. 2, n. 2, 2014.

GONÇALVES, C. S.; RHEINHEIMER, D. S.; KIST, J. B. P.; GASPARETO, A. Qualidade da água em propriedades rurais da microbacia hidrográfica do Arroio Lino - Nova Boêmia - Agudo - RS. Revista Higiene Alimentar, v. 17, n. 113, p. 54-59, 2000. 
GUIMARÃES, A. M.; ALVES, E. G. L.; FIGUEIREDO, H. C. P.; COSTA, G. M.; RODRIGUES, L. S. Frequência de enteroparasitas em amostra de alface (Lactuca sativa) comercializada em Lavras, Minas Gerais. Revista da Sociedade Brasileira de Medicina Tropical, v. 36, n. 5, p. 621-623, 2003.

HOLVOET, K.; SAMPERS, I.; SEYNNAEVE, M.; JACXSENS, L.; UYTTENDAELE, M. Agricultural and management practices and bacterial contamination in greenhouse versus open field lettuce production. International Journal of Environmental Research and Public Health, v. 12, n. 1, p. 32-63, 2014. http://dx.doi.org/10.3390/ijerph120100032

JENSEN, D. A.; FRIEDRICH, L. M.; HARRIS, L. J.; DANYLUK, M. D.; SCHAFFNER, D. W. Cross contamination of Escherichia coli O157:H7 between lettuce and wash water during home-scale washing. Food Microbiology, v. 46, p. 428-433, 2015. http://dx.doi.org/10.1016/j.fm.2014.08.025

JOBBINS, S.E.; ALEXANDER, K.A. Whence they came - antibiotic-resistant Escherichia coli in African wildlife. Journal of Wildlife Diseases, v. 51, n. 4, p. 1-10, 2015. http://dx.doi.org/10.7589/2014-11-257

KONG, P.; HONG, C. Oxygen stress reduces zoospore survival of Phytophthora species in a simulated aquatic system. BMC Microbiology, v. 14, 124, 2014. http://dx.doi.org/10.1186/1471-2180-14-124

LEE, C. C.; JIANG, L. Y.; KUO, Y. L.; HSIEH, C. Y.; CHEN, C. S.; TIEN, C. J. The potential role of water quality parameters on occurrence of nonylphenol and bisphenol A and identification of their discharge sources in the river ecosystems. Chemosphere, v. 91, p. 904-911, 2013. http://dx.doi.org/10.1016/j.chemosphere.2013.02.006

MARQUEZI, M. C.; GALLO, C. R.; DIAS, C. T. S. Comparison of methods for analysis of total coliforms and E. coli in water samples. Revista do Instituto Adolfo Lutz, v. 69, n. 3, p. 291-296, 2010.

MENG, Q.; CHEN, X.; LOBELL, D. B.; CUI, Z.; ZHANG, Y.; YANG, H. et al. Growing sensitivity of maize to water scarcity under climate change. Scientific Reports, v. 6, 19605, 2016. http://dx.doi.org/10.1038\%2Fsrep19605

OLIVEIRA, C. A. L.; GERMANO, M. I. S.; GERMANO, P. M. L. Qualidade das hortaliças. In: GERMANO, P. M. L.; GERMANO, M. I. S. Higiene e vigilância sanitária dos alimentos. São Paulo: Varela, 2001. p. 129-133.

OLIVEIRA, I. M.; JUNQUEIRA, A. M. R. Aspectos da contaminação microbiológica em hortaliças. Brasília: UnB, 2005. Disponível em: http://www.abhorticultura.com.br/ biblioteca/default.asp?id=3447. Acesso em: 19 mar. 2016.

PALÚ, A. P.; TIBANA, A.; TEIXEIRA, L. M.; LEMOS, M. M. A.; PYRRHO, A. S.; LOPES, H. R. Avaliação microbiológica de frutas e hortaliças frescas, servidas em restaurantes self-service privados da Universidade Federal do Rio de Janeiro. Revista Higiene Alimentar, v. 16, p. 67-74, 2002.

PARRON, L. M.; MUNIZ, D. H. F.; PEREIRA, C. M. Manual de procedimentos de amostragem e análise físico-química de água. Colombo: Embrapa Florestas, 2011. Disponível em: https://www.infoteca.cnptia.embrapa.br/bitstream/doc/921050/1/ Doc232ultimaversao.pdf. Acesso em: 19 mar. 2016. 
SCHMIDT, E. I. Estudo e qualidade das águas subterrâneas na região sudoeste do município de Estrela - RS. 2006. 91p. Monografia (Graduação em Ciências Biológicas) - Centro Universitário Univates, Lajeado, 2006.

SINGH, K. P., MALIK, A.; SINHA, S Water quality assessment and apportionment of pollution sources of Gomti river (India) using multivariate statistical techniques - a case study. Analytica Chimica Acta, v. 538, p. 355-374, 2005. http://dx.doi.org/10.1016/j.aca.2005.02.006

STRAWN, L. K.; GRÖHN, Y. T.; WARCHOCKI, S.; WOROBO, R. W.; BIHN, E. A.; WIEDMANNA, M. Risk factors associated with Salmonella and Listeria monocytogenes contamination of produce fields. Applied and Environmental Microbiology, v. 79, n. 24, p. 7618-7627, 2013. http://dx.doi.org/10.1128/AEM.02831-13

TAKAYANAGUI, O. M.; FEBRÔNIO, L. H. P.; BERGAMINI, A. M.; OKINO, M. H. T.; CASTRO E SILVA, A. A. M. C.; SANTIAGO, R.; CAPUANO, D. M.; OLIVEIRA, M. A.; TAKAYANAGUI, M. M. Fiscalização de hortas produtoras de verduras do município de Ribeirão Preto, SP. Revista da Sociedade Brasileira de Medicina Tropical, v. 33, n. 2, p. 169-174, 2000.

VAN DYK, B. N.; DE BRUIN, W.; DU PLESSIS, E. M.; KORSTEN, L. Microbiological food safety status of commercially produced tomatoes from production to marketing. Journal of Food Protection, v. 79, n. 3, p. 392-406, 2016.

VONGKAMJAN, K.; FUANGPAIBOON, J.; TURNER, M. P.; VUDDHAKUL, V. Various ready-to-eat products from retail stores linked to occurrence of diverse Listeria monocytogenes and Listeria spp. isolates. Journal of Food Protection, v. 79, n. 2, p. 239-245, 2016. 